\title{
O CENÁRIO DO ENSINO REMOTO NA ENGENHARIA CIVIL: UMA ANÁLISE DA PERCEPÇÃO DOS PROFESSORES
}

DOI: 10.37702/2175-957X.COBENGE.2021.3461

Kastelli Pacheco Sperandio - kastelli.sperandio@gmail.com

Centro Universitário UNIFACIG

Rua Doutor José Carlos Pires 19

36904-201 - Manhuaçu - MG

Humberto Vinício Altino Filho - humbertovinicio@hotmail.com

Centro Universitário UNIFACIG

Rua Dirceu Lacerda de Castro 74

36906-255 - Manhuaçu - MG

Natália Tomich Paiva Miranda - ntomich@gmail.com

Centro Universitário UNIFACIG

rua josé carlos pires 19

36904-201 - Manhuaçu - MG

Resumo: Este estudo tem como foco a análise da percepção dos professores do curso de Engenharia Civil de um Centro Universitário localizado na Região Leste do Sul de Minas Gerais sobre o Ensino Remoto Emergencial. Sabe-se que o contexto da pandemia da COVID-19 trouxe impactos para os mais diversos setores da sociedade, dentre os quais o cenário educacional que é objeto desta pesquisa. Para investigar as relações mencionadas, além da contextualização do estudo, foram coletados dados por meio de um questionário on-line. Os resultados apontam que os professores vivenciaram uma transição menos brusca de contexto, uma vez que já inseriam elementos da cultura digital em sua prática pedagógica, mas que ainda existem desafios quanto ao envolvimento dos alunos neste modelo emergencial.

Palavras-chave: Ensino Remoto Emergencial; Engenharia Civil; Professor; Contexto Digital. 


\section{O CENÁRIO DO ENSINO REMOTO NA ENGENHARIA CIVIL: UMA ANÁLISE DA PERCEPÇÃO DOS PROFESSORES}

Resumo: Este estudo tem como foco a análise da percepção dos professores do curso de Engenharia Civil de um Centro Universitário localizado na Região Leste do Sul de Minas Gerais sobre o Ensino Remoto Emergencial. Sabe-se que o contexto da pandemia da COVID-19 trouxe impactos para os mais diversos setores da sociedade, dentre os quais o cenário educacional que é objeto desta pesquisa. Para investigar as relações mencionadas, além da contextualização do estudo, foram coletados dados por meio de um questionário on-line. Os resultados apontam que os professores vivenciaram uma transição menos brusca de contexto, uma vez que já inseriam elementos da cultura digital em sua prática pedagógica, mas que ainda existem desafios quanto ao envolvimento dos alunos neste modelo emergencial.

Palavras-chave: Ensino Remoto Emergencial; Engenharia Civil; Professor; Contexto Digital.

\section{Introdução}

As discussões sobre o cenário da educação de forma ampla já abordavam diversas transformações e reconfigurações de papéis, metodologias, abordagens e processos. Diante da pandemia, alguns movimentos metamórficos na educação foram impelidos, potencializados e acelerados, haja vista, por exemplo, a inserção e apropriação de recursos tecnológicos de mediação e suporte aos contextos de aprendizagem.

Diante desse quadro, os papéis do professor e dos alunos como agentes no processo de ensino e aprendizagem figuram como mote de muitas discussões, uma vez que a reorganização das atribuições e responsabilidades nesse processo, bem como a necessidade de desenvolvimento de competências e habilidades imbricadas a esse cenário, trazem à tona novas reflexões que precisaram tornar-se realidade com mais celeridade do que se esperava.

Sendo assim, neste estudo objetivou-se investigar a visão dos professores acerca da solução adotada como forma de manter o contato dos alunos com sua formação: o Ensino Remoto Emergencial. De forma mais específica, a pesquisa trata da percepção dos professores do Curso de Engenharia Civil de um Centro Universitário da região Leste do Sul de Minas Gerais. Para tanto, fez-se a contextualização do estudo e a coleta de dados por meio de uma questionário on-line. Destarte, pretende-se contribuir para as reflexões sobre o Ensino de Engenharia como um todo, tendo como base a óptica dos profissionais formadores.

\section{Ensino Remoto Emergencial e Processos Educacionais}

A pandemia do COVID-19 trouxe consigo diversas transformações sociais, que decerto reverberaram nos contextos educacionais. Dentre essas transformações, o Ensino Remoto Emergencial (ERE) tornou-se pauta de discussões e uma resposta rápida ao fechamento dos ambientes físicos instrucionais, sejam eles da Educação Básica ou da Educação Superior.

Pela impossibilidade de um período adequado de análise de seu formato e construção de modelos e critérios para a implantação dessa solução, esse modelo foi tema 
de amplos debates sobre sua definição e, por muitas vezes, confundido com a modalidade da Educação à Distância (EaD). De acordo com Arruda (2020),

A educação remota emergencial pode ser apresentada em tempo semelhante à educação presencial, como a transmissão em horários específicos das aulas dos professores, nos formatos de lives. Tal transmissão permitiria a colaboração e participação de todos de forma simultânea, mas pode envolver a gravação das atividades para serem acompanhadas por alunos sem condições de assistir aos materiais naquele momento (ARRUDA, 2020, p. 266).

Observando essa definição, fica clara a diferença entre o ERE e a EaD, uma vez que esta é uma modalidade já presente no cenário educacional e como maior estruturação de estratégias, seu formato envolve um "planejamento anterior, consideração sobre perfil de aluno e docente, desenvolvimento a médio e longo prazo de estratégias de ensino e aprendizagem" (ARRUDA, 2020, p. 265); e aquele deu-se como consequência de algo inesperado e segue os moldes do ensino presencial, usando a tecnologia como forma de mediação, valendo-se, principalmente, de momentos síncronos, isto é, momentos em que os estudantes e o professor podem interagir virtualmente em tempo real.

Feita essa diferenciação e, por consequência da mudança repentina dos ambientes de aprendizagem, pode-se trazer à baila a presença das tecnologias em sala de aula e o processo de apropriação de tais recursos pelo professor. De acordo com o estudo Apple Classrooms of Tomorrow-ACOT (1991), tal processo se dá em etapas, como representado abaixo:

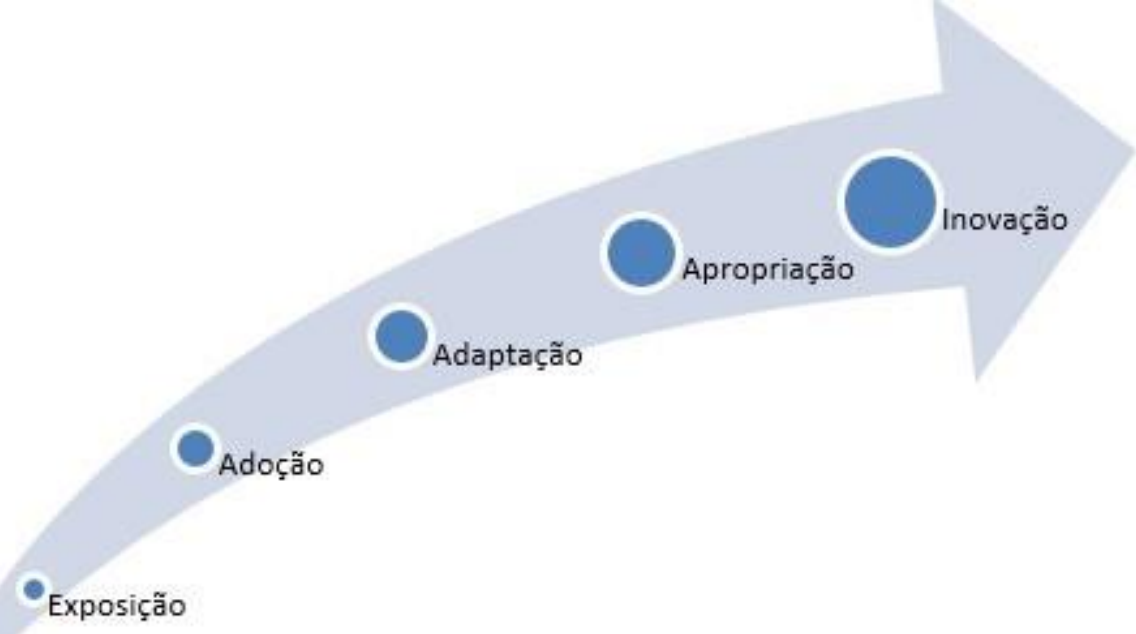

(Fonte: Bacich, 2018)

Como pode-se notar as etapas partem da exposição, isto é, um primeiro contato do professor com a tecnologias educacionais até que ele possa chegar à etapa de apropriação, na qual o docente avalia como e quais os recursos tecnológicos poderão ser um suporte para a aprendizagem dos seus alunos e, após essa etapa, tem-se a inovação, em que o professor utiliza a tecnologia seja ela propriamente educacional ou de outros eixos de forma criativa e inovadora, num movimento transfigurador da sala de aula e para além dela.

Ao observar esse processo percebe-se que, diante da mudança do formato presencial para o ERE, muitos professores e, principalmente aqueles que não estavam em 
contato com tecnologias educacionais, precisaram fazer um grande salto na curva apresentada pelo estudo ACOT. A aceleração do processo de apropriação das ferramentas tecnológicas ficou em grande evidência com os efeitos da pandemia na educação, porém, toda a conjuntura de saberes docentes fora rearranjada, os planejamentos, as relações em sala de aula, as metodologias, os modelos avaliativos.

Sabe-se que, de acordo com Tardif (2002), que o conhecimento profissional dos professores provém de diversos meios como da sua própria história de vida, da sua formação, assim como da sua atuação profissional, sendo essa última sinalizada como uma grande modificadora dos saberes docentes.

Diante disso, e trazendo a discussão para o enfoque da formação em nível superior, importa dizer, com base em Masetto (2012), que outrora sustentou-se "uma crença até pouco tempo inquestionável mantida tanto pela instituição que convidava o profissional a ser professor quanto pela pessoa convidada a aceitar o convite feito: quem sabe, automaticamente sabe ensinar" (p. 15), haja vista a própria concepção de ensinar como sendo "ministrar aulas expositivas ou palestras a respeito de determinado assunto dominado pelo conferencista, mostrar na prática como se fazia - e isso qualquer profissional saberia fazer" (p. 15).

Nessa esteira, tem-se que, se antes de todo essa aceleração de movimentos de transformação e reorganização dos sujeitos envolvidos nos processos educacionais tal crença já se mostrava em declínio, hoje ainda mais se mostra sua incompletude ao tratar do ato distintivo da docência: ensinar, abordado, por Roldão (2007) como uma ação de dupla transitividade, isto é, envolve um algo e um alguém, valorizando, portanto, não só o que se ensina, mas também a quem se ensina e, por sua vez, as relações interpessoais e a interação entre professores e alunos como forma de alcançar o sucesso no processo de ensino e aprendizagem. Fato esse que também é corroborado por Silva e Cecílio (2007) ao discutir a Educação em Engenharia,

A interação professor-aluno assume, então, uma parceria harmoniosa de reciprocidade e colaboração. Dessa forma, a didática tradicional deverá ser superada em nome de uma outra proposta, baseada, agora, no desenvolvimento de procedimentos que propiciem, tanto ao aluno quanto ao professor, a reconsideração de suas práticas por meio de uma relação de troca de conhecimentos por parte do professor para com o aluno e viceversa. (SILVA; CECÍLIO, 2007, p. 69).

Tal insuficiência mostra-se também evidente ao apresentar as competências do professor, que se sustentava unicamente no saber ligado aos conteúdos e práticas, mas demanda domínio de conhecimentos ligados aos pressupostos didático-pedagógicos, isto é, saber ensinar ultrapassa os limites do conhecimento de conteúdo, mas liga-se ainda ao conhecimento pedagógico, ao conhecimento curricular e ao conhecimento pedagógico do conteúdo (SHULMAN, 1987). Silva e Cecílio (2007), ao direcionar essa discussão para a formação em engenharia acrescentam que

ser professor é exercer um trabalho docente que prevê intencionalidade pedagógica, não se confundindo com simples papel de animador, facilitador. A ele cabe a função profissional de orientar os processos de formação do profissional e de desenvolvimento do conhecimento e da autonomia para aprender sempre e, se possível, de modo sintonizado com os padrões produtivos vigentes (SILVA; CECÍLIO, 2007, p. 65). 
Diante dessa discussão, fica evidente a necessidade de investigar as relações e transformações vivenciadas pelos professores que constroem a formação em Engenharia, no contexto educacional célere e transformador vivenciado ao longo dessa transposição de modelos, estratégias, recursos e relações vividas no cenário da Educação Superior.

\section{Metodologia}

Trata-se de um estudo de natureza exploratória e de abordagem qualitativa. Tem-se a pesquisa qualitativa como o mais adequado nesse caso, haja vista a natureza do objeto de estudo: a percepção dos professores. De acordo com Oliveira (2007), essa abordagem se dá como "'um processo de reflexão e análise da realidade através da utilização de métodos e técnicas para compreensão detalhada do objeto de estudo em seu contexto histórico e/ou segundo sua estruturação" (p. 37).

Os participantes da pesquisa são professores do curso de Engenharia Civil de um Centro Universitário da região Leste do Sul de Minas Gerais. Os dados foram coletados por meio de um questionário on-line, composto por 12 perguntas organizadas em 4 seções, a primeira focada na relação do professor com as tecnologias, a segunda sobre o Ensino Remoto Emergencial, a terceira abordava a relação professor-aluno no contexto on-line e a quarta como uma seção livre para comentários de forma geral. Do total de 29 alunos, 12 responderam ao questionário da pesquisa.

\section{Resultados e Discussão}

Nesta seção, será feita a apresentação e discussão dos resultados obtidos por meio do questionário, algumas perguntas serão omitidas por tratarem de assuntos institucionais internos não sendo de forma geral relevantes para o enfoque deste artigo.

Os participantes do estudo são professores do curso de Engenharia Civil, dos quais se obteve a participação de $65 \%$ do corpo docente. Como forma de conhecer, de forma geral, os participantes da pesquisa, tem-se abaixo a distribuição destes por faixa etária.

Gráfico 1: Distribuição dos Participantes por Faixa Etária

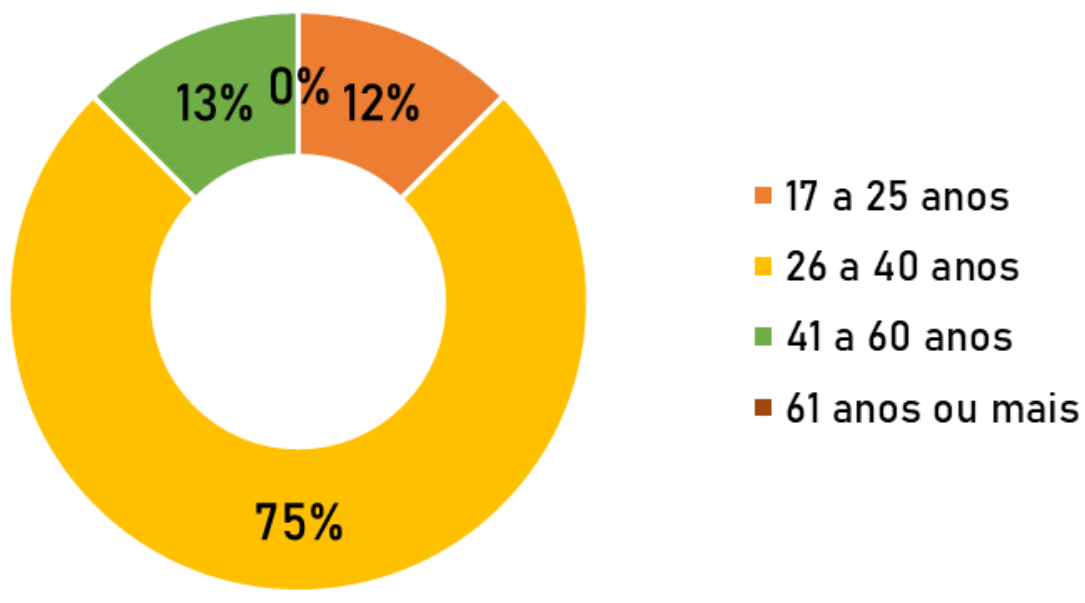

Fonte: Dados da Pesquisa 
Como se pode notar pelo Gráfico 1, a maioria dos professores pertence à faixa etária de 26 a 40 anos. Sendo assim, fazem parte da chamada Geração Y, que tem como marco a vivência da transição entre o analógico e o digital, essa geração, apesar de não estar tão integrada à Internet como a Geração Z, apresenta certo grau de familiaridade com as tecnologias digitais e com a mescla de ambientes on e off-line (COMAZZETTO et al., 2016).

Tal afirmação é corroborada pelo Gráfico 2 (abaixo) em que se pode observar um grau de familiaridade, no mínimo, satisfatório entre os professores e as tecnologias. Sendo que a maioria indica que tem grande familiaridade com esses recursos.

Gráfico 2: Grau de Familiaridade com as Tecnologias

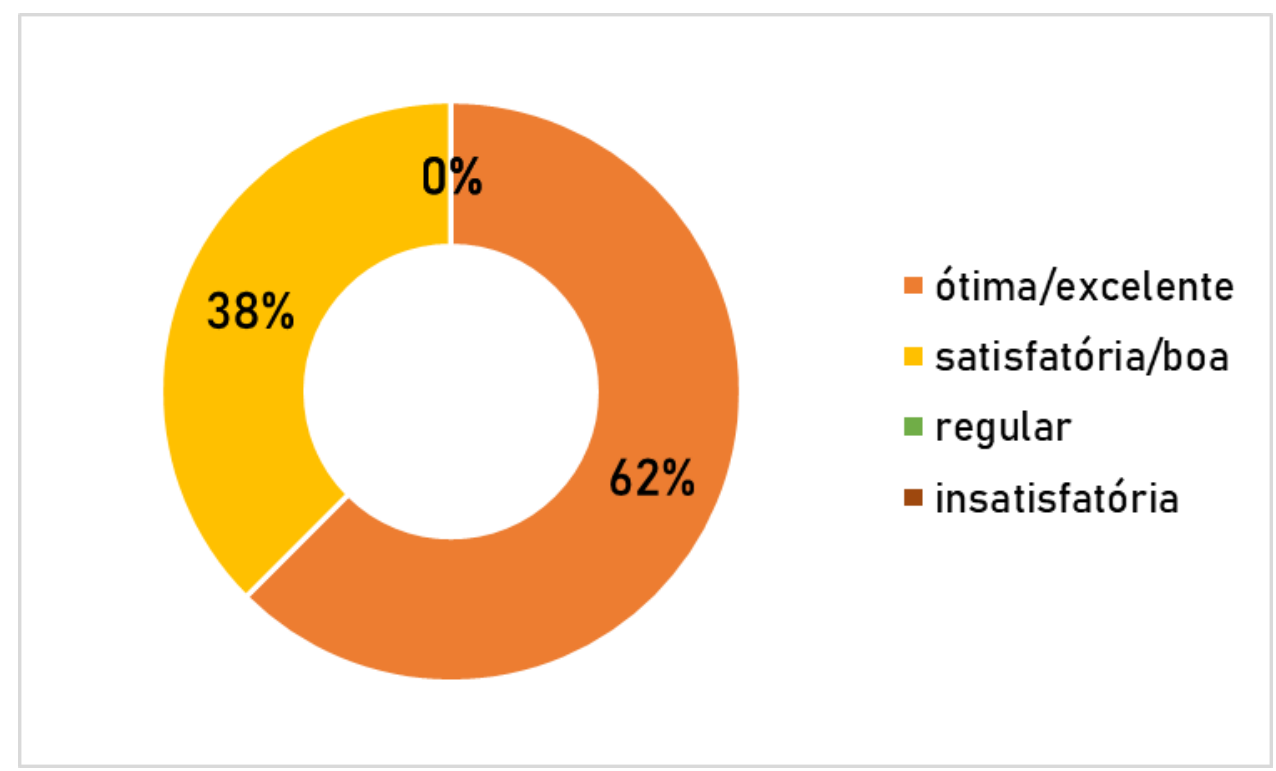

Fonte: Dados da Pesquisa

Nas próximas duas questões, o objetivo é conhecer as ferramentas e recursos digitais que os participantes têm utilizado no dia a dia e em sala de aula.

Gráfico 3: Ferramentas Digitais utilizadas no cotidiano dos participantes

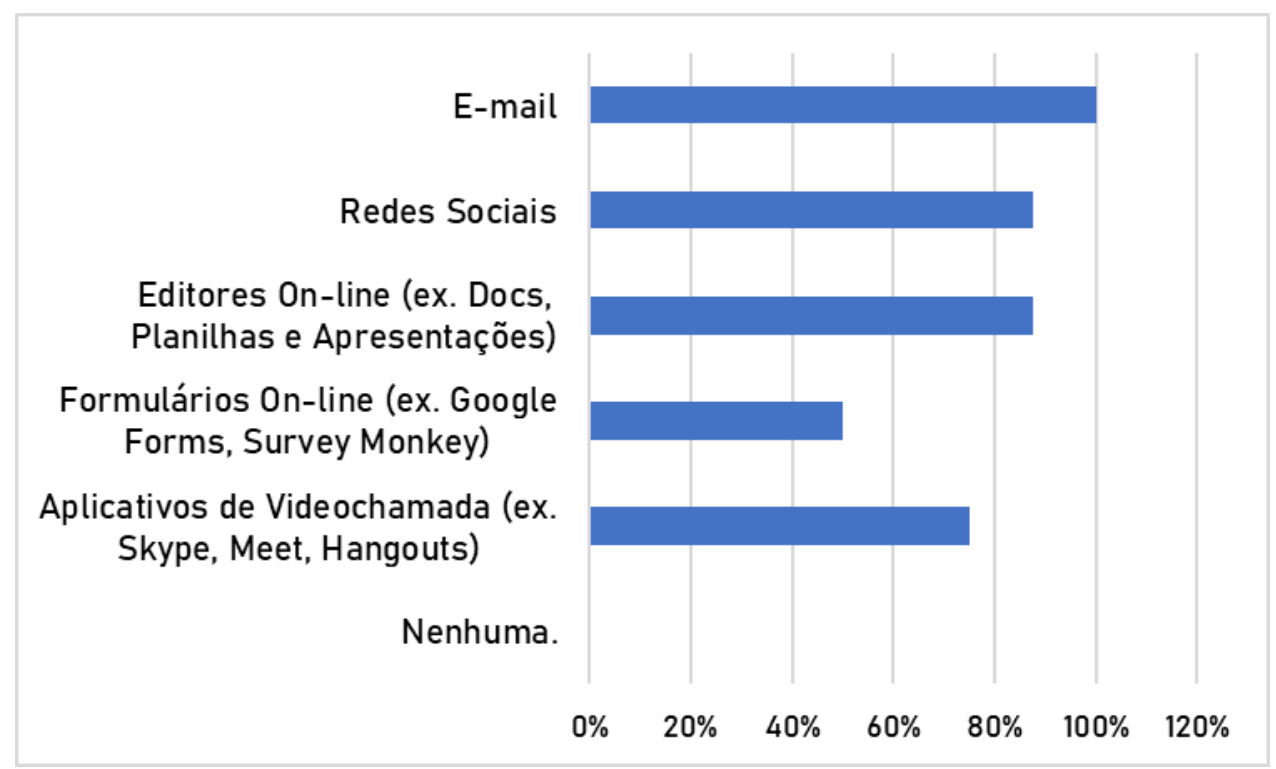

Fonte: Dados da Pesquisa 
Gráfico 4: Ferramentas Digitais utilizadas pelos participantes em sala de aula

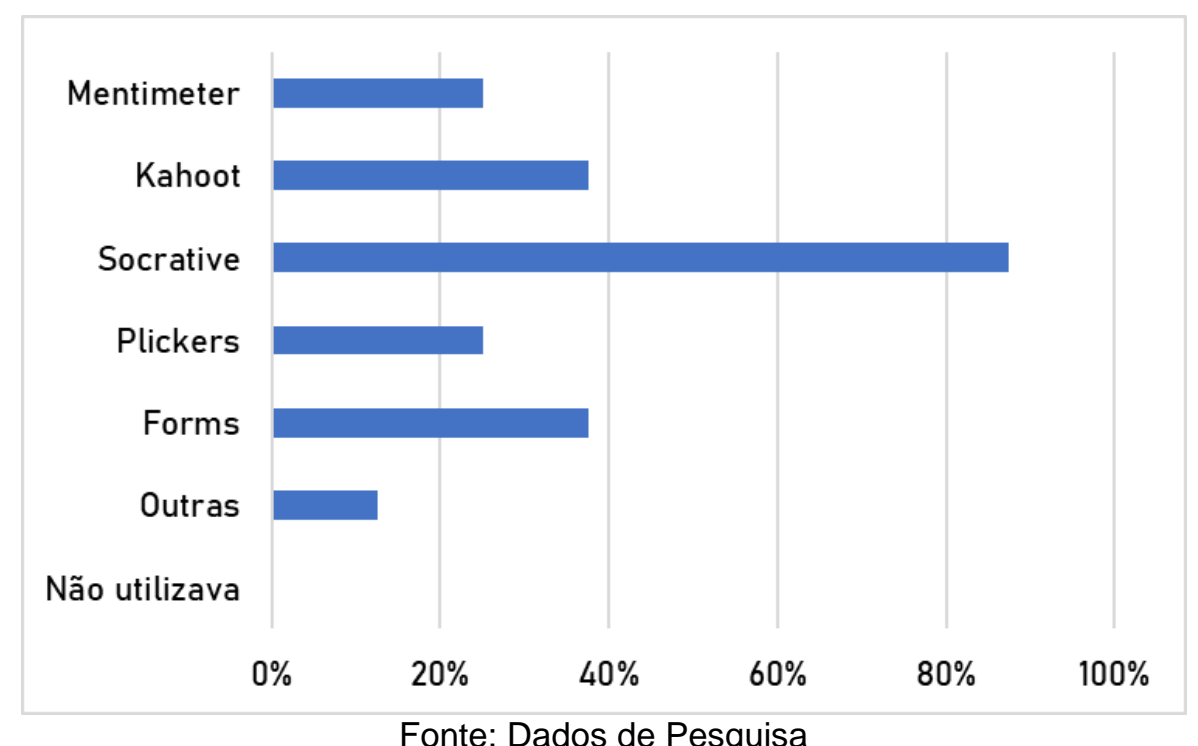

Pela leitura dos gráficos, pode-se observar que os professores já utilizavam diversos recursos tecnológicos dentro e fora da sala de aula. Tal constatação é importante, pois, dessa forma, entende-se que os professores do curso de Engenharia Civil não foram submetidos ao salto repentino na curva de apropriação de recursos tecnológicos construída por meio do estudo ACOT. Muitos já se encontravam, pelo menos, na fase de adoção de tecnologias educacionais, uma vez que já empregavam aplicativos como Mentimeter, Kahoot, Plickers, Socrative e Forms ou ainda outras plataformas como suporte às experiências de aprendizagem.

Cabe ressaltar também que os aplicativos de videochamada amplamente difundidos no cenário do ERE, já faziam parte das ferramentas utilizadas por quase $80 \%$ dos professores participantes.

Esse contexto, prenuncia os resultados apresentados no Gráfico 5 (abaixo) em que os professores atestam o potencial da tecnologia como ferramenta de suporte ao processo de ensino e aprendizagem.

Gráfico 5: Avaliação do Potencial das Tecnologias como ferramenta de Ensino e Aprendizagem.

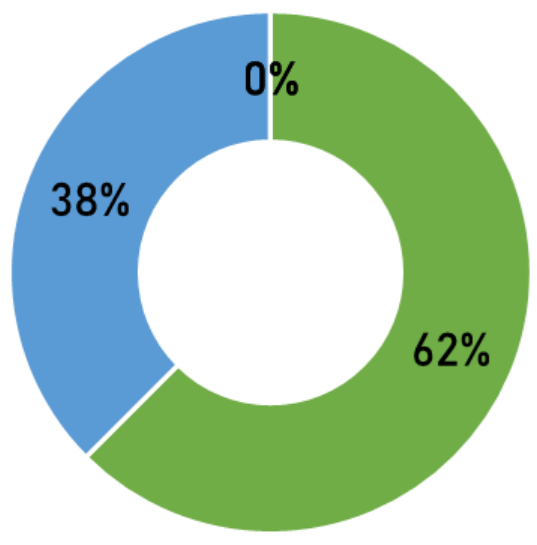

- ótimo/excelente

- satisfatório/bom

- regular

- insatisfatório

Realização: 
Fonte: Dados da Pesquisa

Nos próximos dois gráficos, será feita a comparação entre as expectativas e a avaliação dos professores quanto ao Ensino Remoto Emergencial, antes do início de sua utilização e depois de decorrido certo tempo de vivência.

Gráfico 6: Expectativa dos Professores para o Ensino Remoto

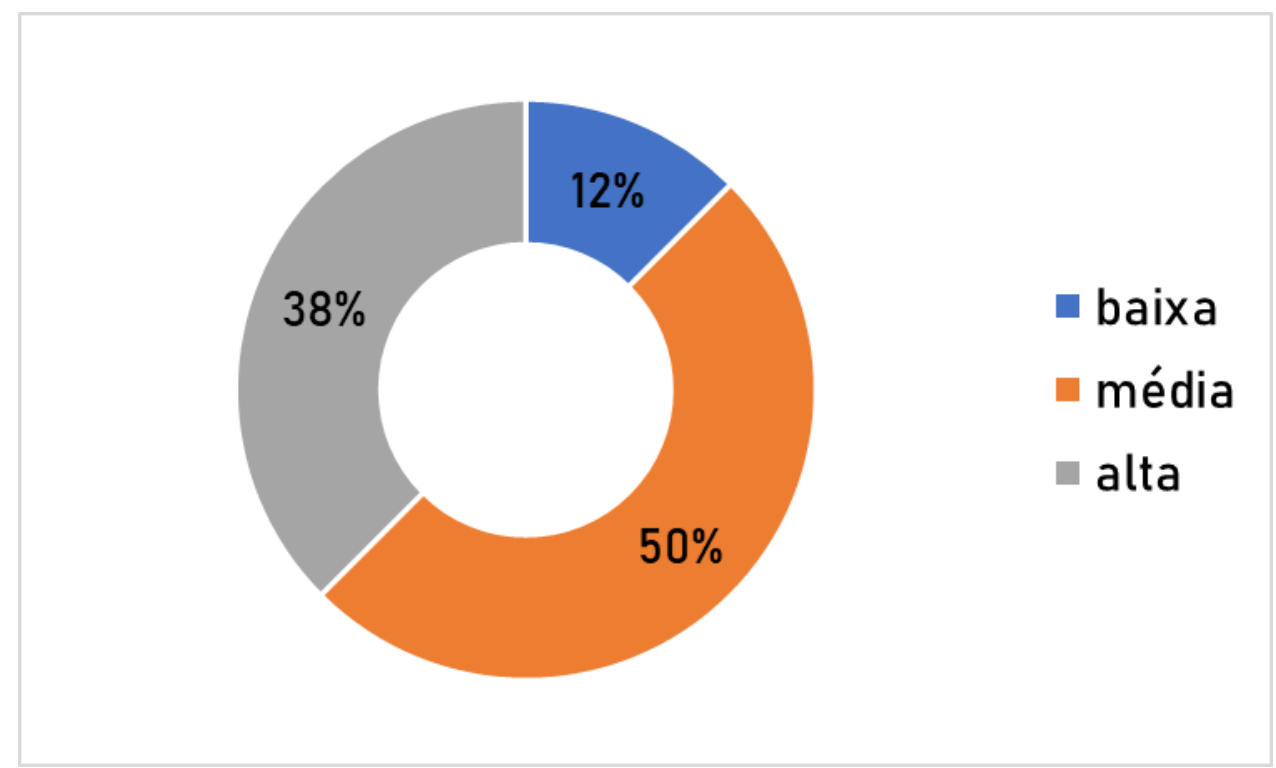

Fonte: Dados da Pesquisa

Gráfico 7: Avaliação do Ensino Remoto após o Início das Aulas

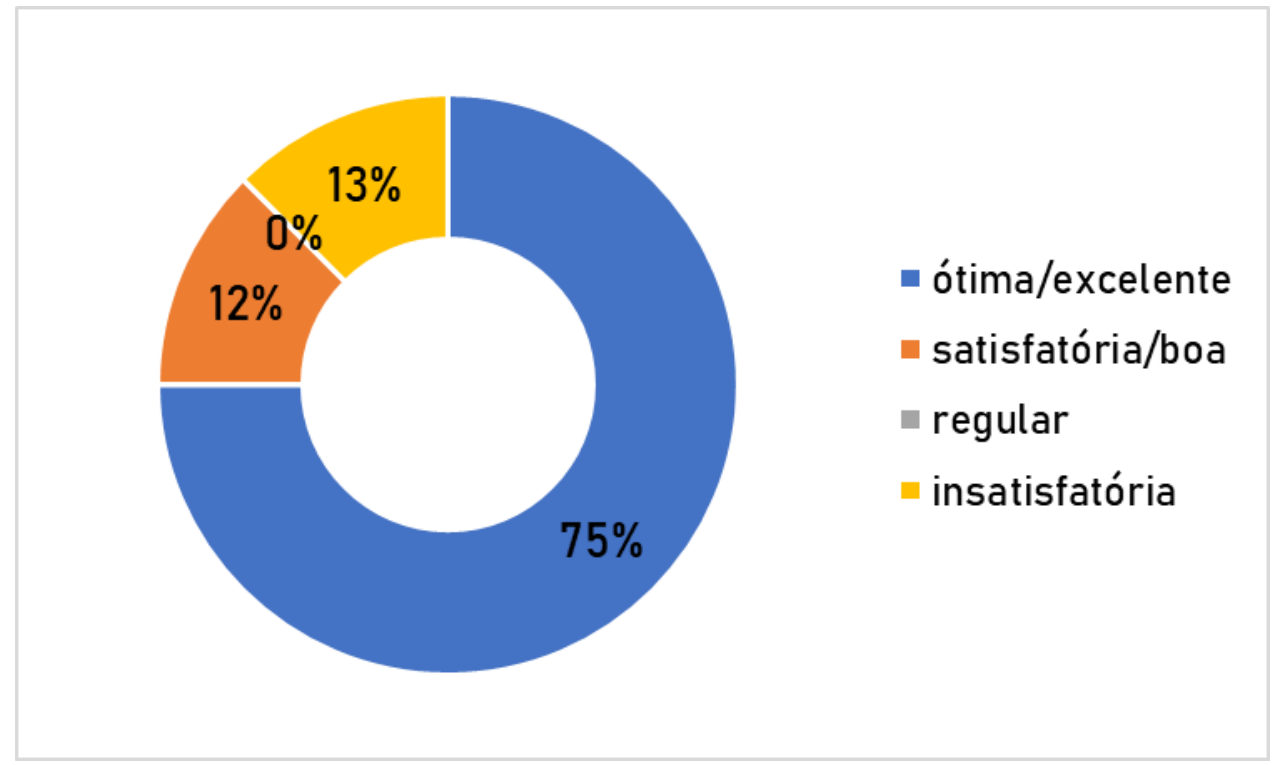

Fonte: Dados da Pesquisa

Como se pode observar pelos Gráficos 6 e 7, as expectativas dos docentes do curso de Engenharia Civil foram superadas quando vivenciaram o ERE na prática, uma vez que antes tem-se cerca de $62 \%$ dos professores apontaram uma expectativa média/baixa, e depois temos $87 \%$ avaliando o modelo como bom/excelente. 
A superação de expectativas negativas por um resultado positivo pode dar o tom de uma transformação mais acelerada na concepção do ensinar dentro do cenário da Educação em Engenharia, como já vinham apontando Silva e Cecílio (2007).

Essa satisfação também é reafirmada quando os professores são questionados sobre o encontro ao vivo.

Gráfico 8: Avaliação dos Professores sobre as Aulas Ao Vivo

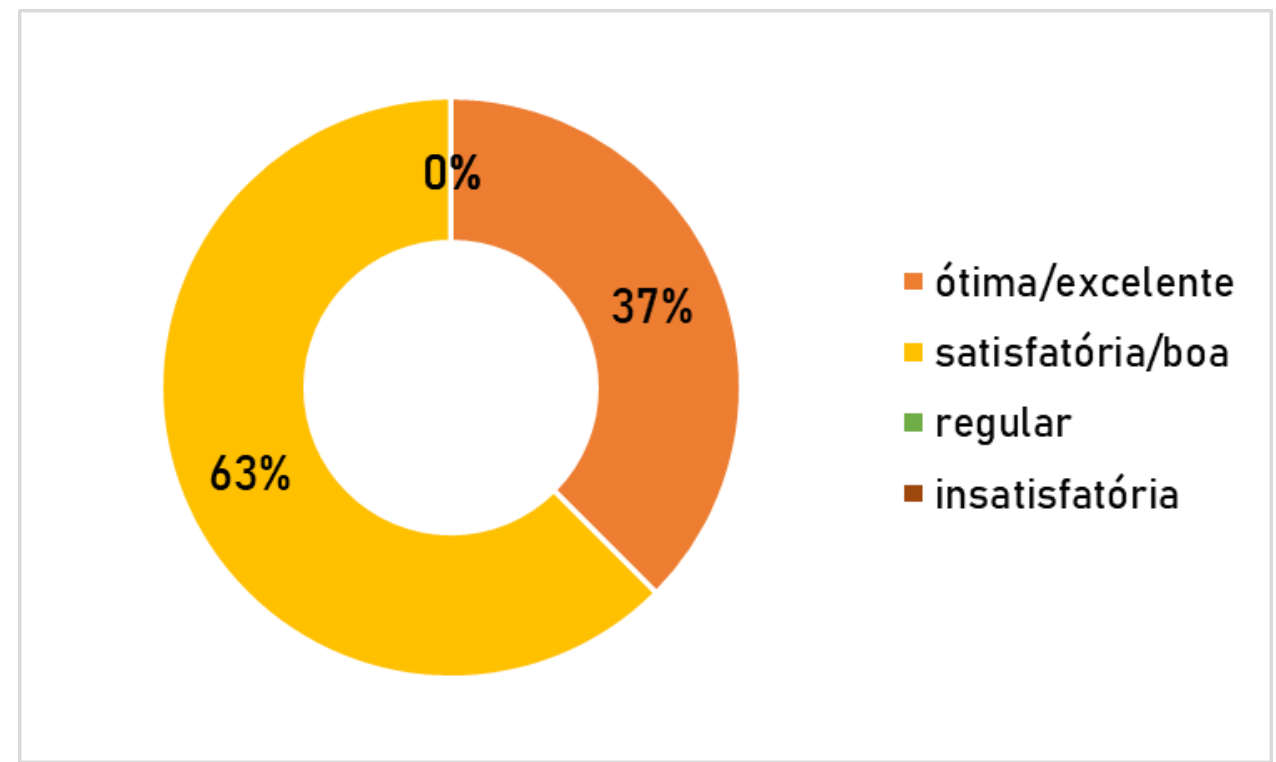

Fonte: Dados da Pesquisa

Como se pode notar pelo Gráfico 8, a maioria dos professores está satisfeito com a aula ao vivo, que no caso da instituição analisada, mantém a mesma duração, horário, organização das turmas do ensino presencial. Porém, o Gráfico 9 (abaixo) apresenta um ponto de atenção para esse momento.

Gráfico 9: Grau de Envolvimento dos Alunos nas Aulas

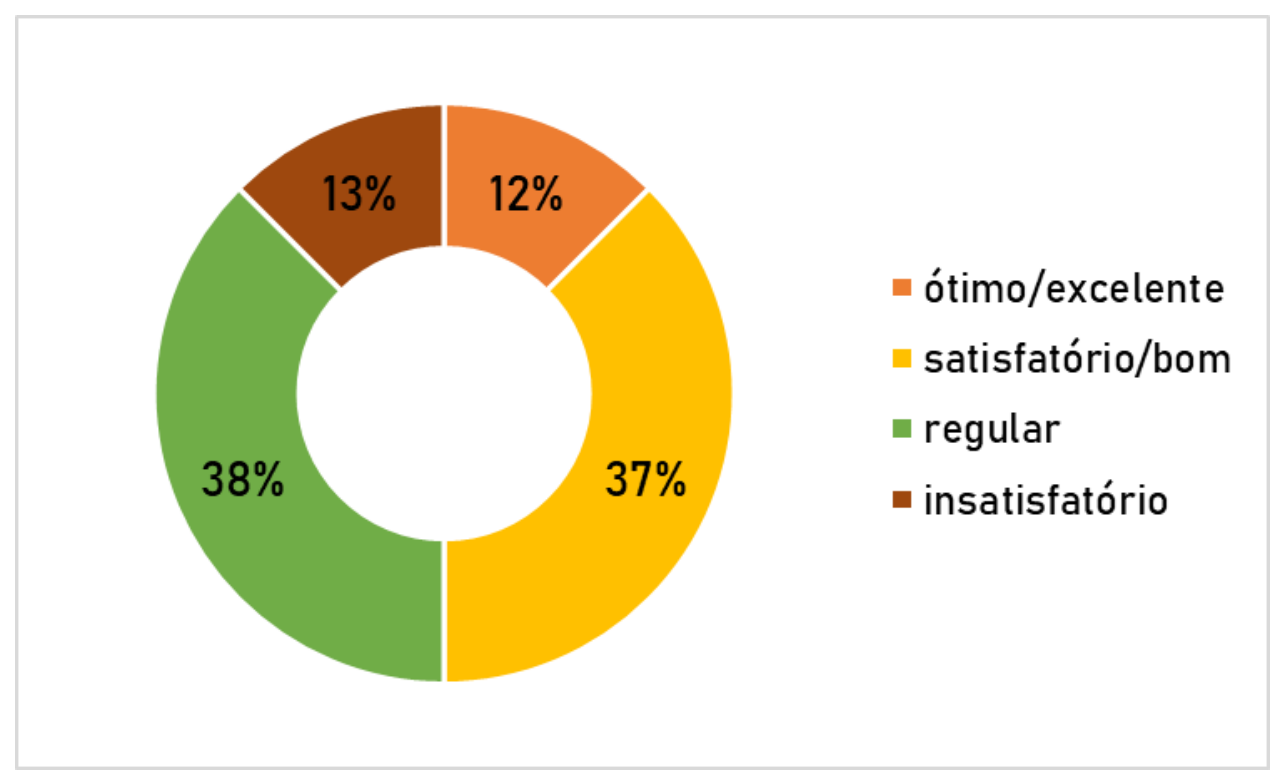

Fonte: Dados da Pesquisa 
De acordo com o Gráfico 9, pode-se perceber ainda um problema do ERE que é o envolvimento e a interação entre professor-aluno e aluno-aluno.

Tal afirmação é exemplificada e corroborada pelas respostas obtidas na questão discursiva, que como não era obrigatória foi respondida por poucos professores:

(1) A maior dificuldade das aulas oferecidas em plataformas digitais é colocar os alunos como protagonistas do processo de aprendizagem, pois muitos deles não possuem ou ligam as câmeras e os microfones durantes as aulas, e, por isso, participam pouco durante as aulas. Até utilizar as metodologias ativas que já acostumávamos a usar durante as aulas presenciais e que atraia a atenção e participação dos alunos têm sido mais difíceis.

(2) Minha experiência está sendo boa, noto sempre participações dos alunos, pena que sempre são os mesmos que participavam na sala de aula. No meu caso, área de exatas, as aulas online estão demandando mais trabalho pois tento descrever tudo nos slides para ver se fica mais fácil para os alunos compreenderem o assunto, já que só falar não resolve nesse caso. Mas está sendo uma ótima oportunidade de ensinar de uma forma diferente.

(3) Os alunos interessados conseguem adquirir o conhecimento, independentemente da metodologia utilizada. Contudo, percebo que alguns alunos estão seguindo a filosofia do "mínimo esforço", algo que, neste ambiente, fica complexo administrarmos como professores. Em relação a crítica pessoal, percebo que precisamos evoluir nesse meio, para isso, sugiro um grupo de discussão junto ao TEIA onde possamos trocar experiências, boas práticas e com isso evoluirmos mais rápido.

(4) As aulas on-line são adequadas para passar por este problema, mas na minha opinião não substituem as aulas presenciais totalmente. Fica complicado observar a reação de todos os alunos. Alguns alunos não interagem como na aula presencial.

(5) Surpreso com a presença dos alunos e participação muito boa

Como se pode notar pelas respostas, os professores não se encontram insatisfeitos ou desmotivados por essa solução que vem sendo empregada durante a pandemia. Porém, muitos apontam preocupações com a construção do conhecimento e com a interação em sala de aula, que de certa forma está mais difícil nesse contexto. Algo que já mostra uma mudança nas concepções do professor sobre o ensinar, considerando por essas respostas os dois pontos importantes de transitividade trazidos por Roldão (2007): o que se ensina e a quem, valorizando não só o conteúdo, mas também os sujeitos envolvidos no processo.

Vale ressaltar também que os professores afirmam que continuaram a trazer elementos das metodologias ativas e tecnologias para sala de aula, fazendo a devida adaptação e até mesmo apontaram a atuação do TEIA (setor de formação docente da instituição) como suporte estratégico para acelerar a apropriação e troca de experiências.

\section{Considerações Finais}

Este artigo teve como objetivo investigar a percepção dos professores do curso de Engenharia Civil de um Centro Universitário localizado na Região Leste do Sul de Minas Gerais sobre o Ensino Remoto Emergencial, como forma de contribuir para as reflexões e ações no contexto da Educação em Engenharia.

A partir das discussões e dos dados apresentados, pode-se concluir que os professores estão se adaptando de forma satisfatória a esse cenário e seus conhecimentos e experiências prévias com as tecnologias, bem como outros fatores que compõem as situação de construção de saberes docentes, contribuíram de forma significativa para que essas transição fosse vivenciada de forma mais branda, uma vez que não foi possível fazêla de forma lenta e gradual como ocorre na maioria dos processos de transformação educacional.

A visão dos professores aponta de forma geral uma realidade positiva sobre o ERE, algo que é de grande importância, uma vez que a adaptação a um quadro de constantes 
mudanças é condição sine qua non para os profissionais deste século, como apontam diversos estudo socioeconômicos.

A partir das reflexões, abrem-se ainda lacunas para a investigação sobre as dificuldades apresentadas no engajamento e interação com os alunos nesse contexto, sobre as concepções docentes de sua função social e sobre os avanços da tecnologia e sua influência na Engenharia Civil intra e extramuros das Instituições de Ensino Superior.

\section{Referências}

ACOT. Apple Classrooms of Tomorrow: Philosophy and Structure and What's Happening Where. Apple Computer, Inc., Cupertino, CA, 1991.

ARRUDA, Eucidio Pimenta. Educação remota emergencial: elementos para políticas públicas na educação brasileira em tempos de Covid-19. EmRede-Revista de Educação a Distância, v. 7, n. 1, p. 257-275, 2020.

BACIH, Lilian. Etapas de apropriação das tecnologias digitais. 2018. Disponível em: https://lilianbacich.com/2018/08/09/etapas-de-apropriacao-das-tecnologias-digitais/.

Acesso em: 15 abr. 2021.

COMAZZETTO, Letícia Reghelin et al. A geração $Y$ no mercado de trabalho: um estudo comparativo entre gerações. Psicologia: ciência e profissão, v. 36, n. 1, p. 145-157, 2016.

MASETTO, Marcos Tarciso. Competências pedagógicas do professor universitário. São Paulo: Summus, 2012.

OLIVEIRA, Maria Marly de. Como Fazer Pesquisa Qualitativa. Petrópolis: Vozes. 2007.

ROLDÃO, Maria do Céu. Função docente: natureza e construção do conhecimento profissional. Revista brasileira de educação, v. 12, n. 34, p. 95, 2007.

SHULMAN, Lee. Knowledge and teaching: Foundations of the new reform. Harvard educational review, v. 57, n. 1, p. 1-23, 1987.

SILVA, Leandro Palis; CECÍLIO, Sálua. A mudança no modelo de ensino e de formação na engenharia. Educação em Revista, Belo Horizonte, v. 45, p. 61-80, 2007.

TARDIF, Maurice. Saberes docentes e formação profissional. 2. ed. Petrópolis: Vozes, 2002.

\section{THE REMOTE TEACHING SCENARIO IN CIVIL ENGINEERING: TEACHERS PERCEPTION ANALYSIS}

Abstract: We already know that COVID-19 pandemic had a great impact on the most diverse sectors of society, including the educational scenario. This study aims to analyse the perception of teachers and students of Civil Engineering course of a University Center about Emergency Remote Teaching. Data were collected through an online questionnaire and the results showed that teachers experienced a less abrupt transition for the remote 
teaching than the students. Probabily because they had already insert elements of digital culture in their pedagogical practice.

Keywords: Emergency Remote Teaching; Civil Engineering; Teacher; Digital Context. 